School of Management, Swansea University, Swansea, UK

2 Department of Medical Social Sciences, Feinberg School of Medicine, Northwestern University, Chicago, IL, USA

3 Center for Policy Impact in Global Health, Duke Global Health Institute Duke University, Durham, NC, USA

Correspondence to: S Williams simonwilliams@northwestern.edu Cite this as: BMJ 2021;374:n2019 http://dx.doi.org/10.1136/bmj.n2019 Published: 19 August 2021

\title{
How universities can make reopening safer this autumn
}

\section{Universities should consider five key factors ahead of the start of the new academic year, say Simon Williams and Gavin Yamey}

\author{
Simon N Williams, ${ }^{1,2}$ Gavin Yamey ${ }^{3}$
}

One year ago, when universities in the United States reopened for their fall semester, the outcome was disastrous. At that time the US had about 55000 new daily cases and had "no federal covid-19 control plan or coordinated vision for safely reopening universities." In the United Kingdom, like the US, chaotic reopenings sparked outbreaks that plunged "entire flats and halls of residence into lockdown." 3

Now, with universities on both sides of the Atlantic again set to reopen, higher education institutions are "once again confronting the challenges posed by SARS-CoV-2 in their planning for safe operations during the approaching academic year." 4 The challenges are heightened by the delta variant, which is estimated to be twice as transmissible as the original coronavirus strain and is now dominant in the US and the UK. ${ }^{5}$

It remains critically important to protect students from covid-19. While it's true that covid-19 rarely kills young adults, they certainly can become ill and can also develop long term symptoms: studies suggest that about $10 \%$ of infected people at any age can develop long covid. ${ }^{6}$ Infected students can infect older, vulnerable adults on campus, including teachers and university maintenance or service staff. Evidence also shows that campus outbreaks can drive infection in the communities around the university. ${ }^{7}$

So, what steps can universities take to make autumn reopening safer? We believe that there are five key considerations.

\section{Key factors}

First and foremost is the level of vaccination coverage. A new modelling study has found that colleges that achieve vaccine coverage of over $90 \%$ may safely return to normality. ${ }^{4}$ In other words, say the study authors, "campus activities can be fully resumed while holding cumulative cases below $5 \%$ of the population without the need for routine, asymptomatic testing." ${ }^{4}$ Such high coverage rates will be difficult to attain unless colleges have a mandate-and indeed many US colleges and universities require all students, staff, and faculty to be vaccinated before returning this autumn. ${ }^{8}$ If vaccination coverage is below $90 \%$, colleges will have to rely on measures such as regular testing, masking, and distancing to keep campuses safe.

Students in England, at the time of writing, will not be required to show proof of vaccination. ${ }^{9}$ The government is trying out various incentive schemes, as well as vaccine passports in nightclubs, to boost the number of young people getting vaccinated. ${ }^{10} 11$
The reasons for vaccine hesitancy are complex, but one is a lack of urgency due to a reduced perception of individual risk and the inconvenience of making appointments. ${ }^{12}$ Universities can increase uptake by offering vaccinations on site. Planning ahead, discussions for booster jabs are under way-in the UK, vulnerable groups are due to be offered them from September ${ }^{13}$-and health service and vaccine providers can work with universities to facilitate and increase uptake of booster jabs on campuses.

Second, universities on both sides of the Atlantic are considering delaying or phasing in their autumn reopening or incorporating a blended learning approach. Universities should consider a phased return to avoid a mass migration of all of their students over a matter of weeks (the UK, for example, has about two million higher education students).

Third, wherever possible, universities, governments, and other relevant stakeholders and funders should invest in ensuring adequate ventilation throughout campuses, including in classrooms and accommodation. Between now and the start of the academic year there's sufficient time for substantial investment in high efficiency particulate air (HEPA) filters and $\mathrm{CO}_{2}$ monitors to ensure adequate ventilation throughout university buildings. ${ }^{14}$

This investment will provide benefits not just in the short term in relation to covid-19 but also in the longer term, for covid and other respiratory diseases including "freshers' flu," a group of illnesses caused by various viruses. ${ }^{15}$ In the initial weeks of term, outdoor classrooms and social spaces should be introduced and encouraged where possible.

Fourth, effective contact tracing, combined with effective on-campus testing, isolation, and support, is key to minimising the effects of transmission on and beyond campuses. And additional resources to ensure adequate support for self-isolation should be made available, to encourage adherence and mitigate any negative impact of self-isolation. ${ }^{16}$

\section{Masking}

Finally, masks still have a role to play in certain circumstances. In the US, the Centers for Disease Control and Prevention recently changed its guidance to say that everyone, not just unvaccinated people, should wear a mask indoors in places with high levels of transmission. ${ }^{17}$ Its new guidance was based on data suggesting that, if a vaccinated person becomes infected, the cycle threshold value-an indication of how much virus a person is carrying - may be the same as in an unvaccinated infected person. ${ }^{18}$ Some US universities, such as Duke University, are making indoor masking mandatory along with vaccination. ${ }^{19}$ 
Public opinion in the UK and the US remains favourable towards maintaining face masks, particularly in crowded settings. ${ }^{2021}$ Social distancing in large classrooms should be retained in certain circumstances, such as where local community rates are high. Where this is not possible, and where large group classrooms (for example, lecture halls) are deemed pedagogically important, masks should be required as a precautionary measure for the initial phase after reopening.

Competing interests: SW declares none. GY declares that he is a signatory to the People's Vaccine Campaign and is a funding member of Amnesty International, one of the members of the People's Vaccine Alliance. He was a member of the Covid-19 Vaccine Development Taskforce, hosted by the World Bank, and participated as an academic unpaid adviser in the consultation process that led to the launch of Covax, a global covid-19 vaccine sharing mechanism. He has received grant funding from WHO; Gavi, the Vaccine Alliance; and the Bill \& Melinda Gates Foundation.

Provenance and peer review: Commissioned; not externally peer reviewed.

1 Yamey G, Walensky RP. Covid-19: re-opening universities is high risk. BMJ2020;370:m3365. doi: 10.1136/bmj.m3365 pmid: 32873595

2 Tracking coronavirus cases at US colleges and universities. New York Times 2020 Dec 31. https://www.nytimes.com/interactive/2020/us/covid-college-cases-tracker.html

3 Shadwell E. University coronavirus chaos: thousands of students in halls lockdown "with no support”. Daily Mirror 2020 Sep 25. https://www.mirror.co.uk/news/uk-news/university-coronavirus-chaos-hundreds-halls-22744758

4 Paltiel D, Schwartz J. Assessing covid prevention strategies to permit the safe opening of college campuses in fall 2021. medRxiv 2021.07.19.21260522. doi: 10.1101/2021.07.19.21260522

5 Reardon S. How the delta variant achieves its ultrafast spread. Nature 2021 Jul 21. https://www.nature.com/articles/d41586-021-01986-w

6 Greenhalgh T, Knight M, A'Court C, Buxton M, Husain L. Management of post-acute covid-19 in primary care. BMJ2020;370:m3026. doi: 10.1136/bmj.m3026 pmid: 32784198

7 Andersen M, Bento Al, Basu A, Marsicano C, Simon K. College openings, mobility, and the incidence of covid-19.medRxiv 2020.09.22.20196048. doi: 10.1101/2020.09.22.20196048

8 Dickler J. Hundreds of colleges say covid vaccines will be mandatory for fall 2021. CNBC2021 May 11. https://www.cnbc.com/2021/05/11/hundreds-of-colleges-to-require-covid-vaccines-forfall-2021.html

9 Morton B. Covid vaccine will not be compulsory for university lectures. BBC News 2021 Jul 31. https://www.bbc.co.uk/news/uk-58040302.amp

10 Savage M. Uber and Deliveroo discounts to lure young people in UK to get covid jab. Guardian 2021 Aug 1. https://www.theguardian.com/world/2021/aug/01/discounts-uber-deliveroo-lureyoung-people-in-uk-covid-jab-vaccinations

11 Stewart H. Covid vaccine certificates to be compulsory for crowded venues in England. Guardian 2021 Jul 19. https://www.theguardian.com/world/2021/jul/19/covid-certificates-to-be-compulsoryfor-crowded-venues-in-england

12 Williams SN, Dienes K. Public attitudes to covid-19 vaccines: a qualitative study.medRxiv 2021.05.17.21257092. doi: 10.1101/2021.05.17.21257092.

13 Department of Health and Social Care, UK Government. Most vulnerable could be offered booster covid-19 vaccines from September. 30 Jun 2021. https://www.gov.uk/government/news/mostvulnerable-could-be-offered-booster-covid-19-vaccines-from-septem-

ber\#: :text=The\%20JCVI\%20's\%20interim\%20advice,the\%20annual\%20flu\%20vaccination\%20programme

14 SAGE-EMG. Potential application of air cleaning devices and personal decontamination to manage transmission of covid-19. 4 Nov 2020. https://assets.publishing.service.gov.uk/government/uploads/system/uploads/attachment_data/file/939173/S0867_EMG_PotentiaL_application_of_air_cleaning_devices_and_personal_decontamination_to_manage_transmis sion_of_COVID-19.pdf

15 Gatherer D. Explainer: what is freshers' flu and what can you do about it? Conversation 2015 Oct 6. https://theconversation.com/explainer-what-is-freshers-flu-and-what-can-you-do-about-it48400

16 Cevik M, Baral SD, Crozier A, Cassell JA. Support for self-isolation is critical in covid-19 response. BMJ2021;372:n224. doi: 10.1136/bmj.n224 pmid: 33504501

17 Aubrey A. CDC urges vaccinated people to mask up indoors in places with high virus transmission. NPR2021 Jul 27. https://www.npr.org/sections/health-shots/2021/07/27/1021206558/cdc-expected-to-change-mask-guidance-for-vaccinated-people-including-in-schools

18 Brown CM, Vostok J, Johnson H, et al. Outbreak of SARS-CoV-2 infections, including covid-19 vaccine breakthrough infections, associated with large public gatherings-Barnstable County, Massachusetts, July 2021. MMWR Morb Mortal Wkly Rep 2021; published online 30 Jul. doi: http://dx.doi.org/10.15585/mmwr.mm7031e2

19 Quillin M. Most area colleges say they will require masks in classrooms as fall semester starts. News \& Observer 2021 Jul 29. https://www.newsobserver.com/news/local/counties/wakecounty/article253057203.html

20 Ballard J. Most Britons want covid restrictions to remain-poll. Reuters 2021 Jul 15. https://www.reuters.com/world/uk/most-britons-want-covid-restrictions-remain-poll-2021-07$14 /$
21 Ipsos Mori. As delta surges, poll data suggests that unvaccinated America's opposition to the shots is declining. 3 Aug 2021. https://www.ipsos.com/en-us/news-polls/axios-ipsos-coronavirusindex 